\title{
Evaluation of combined biochemical markers in the diagnosis of acute coronary syndrome in Nineveh governorate
}

\author{
Samir B Al-mukhtar*, Akram J Ahmad** \\ Departments of Biochemistry, ${ }^{*}$ Nineveh College of Medicine, \\ **Mosul College of Medicine, University of Mosul
}

$\underline{\text { Received }} \quad \underline{\text { Accepted }}$

12.6.2011
30.10.2011

\section{ABSTRACT}

Objective: To evaluate the importance of combination of biochemical markers in patients with Acute Coronary Syndrome (ACS) and to determine the optimal biochemical strategy for highly sensitive, early diagnosis of myocardial injury.

Patients and methods: This study was carried out in coronary care unit in Ibn- Sena Teaching Hospital in Mosul city from January to November, 2008. Two hundred and forty nine patients with (ACS) presented with chest pain and one hundred and eleven apparently healthy subjects. Four cardiac markers Creatine Kinase (CK) and Creatine Kinase-MB (CK-MB) activities (markers of necrosis), myoglobin (marker of muscle injury), and troponin I (marker of necrosis) were estimated in addition to CKMB index. The collected data were analyzed by chi square, unpaired t-test and analysis of variance (ANOVA). Receiver Operating Characteristics (ROC) analysis was used to assess the role of selected parameters in the diagnosis of ACS and to determine optimal cut-off values for all biochemical markers.

Results: The optimal cut-off value of each of 5 parameters with reasonable validity were used to define single test criteria. The serum troponin I was with highest validity among other parameters. The serum troponin I was used in combination with each of the remaining 4 criteria and the test performance was assessed. All combinations were associated with higher specificity than that of serum troponin I alone. However, the accuracy of serum troponin I alone $94.0 \%$ was higher than the accuracy of all other combinations.

Conclusion: The study has suggested that combining troponin I, myoglobin and CKMB index yields satisfactory diagnostic sensitivity and thus provide valuable information for clinicians in managing Acute Coronary Syndrome (ACS).

Key words: Troponin I, myoglobin, Creatine Kinase (CK), Creatine Kinase-MB (CK-MB), CK-MB index, acute coronary syndrome, biochemical markers.

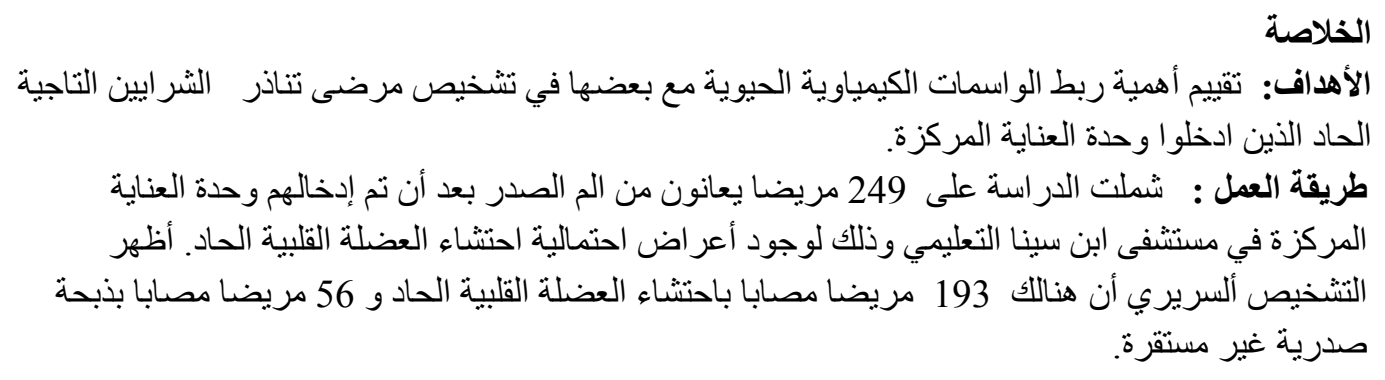




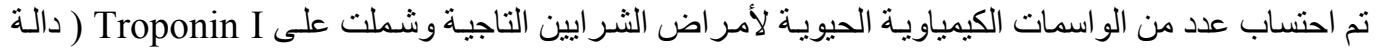

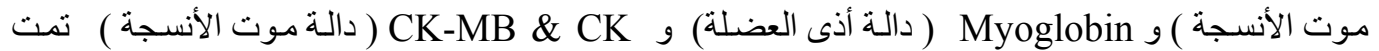

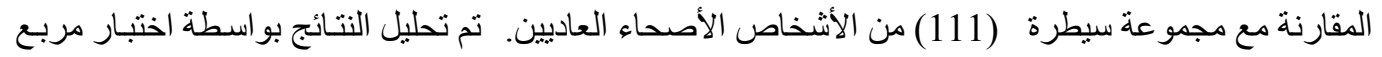
كاى و جدول تحليل التباين و اختبار تى . واستخدمت طريقة أل ROC لبيان حساسية و خصوصية المتغيرات و لإثبات دور ها في تشخيص المرض والتفريق بين احتشاء العضلة القلبية والذبحة القلبية غبر المستقرة.

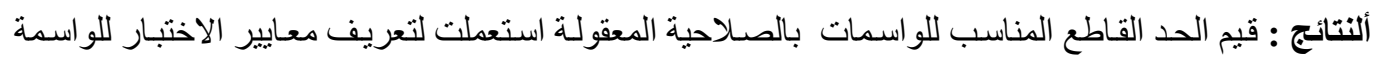

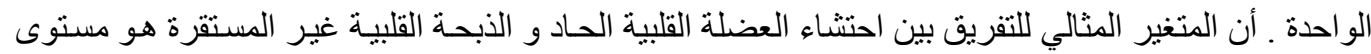

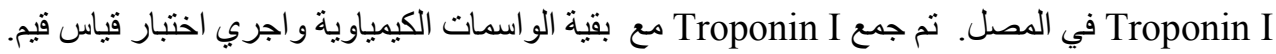

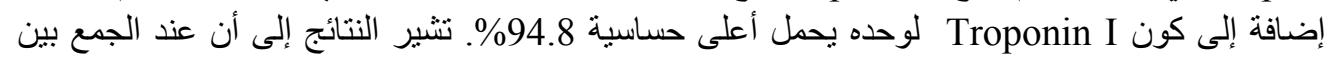

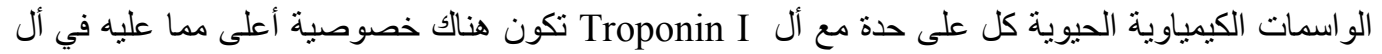

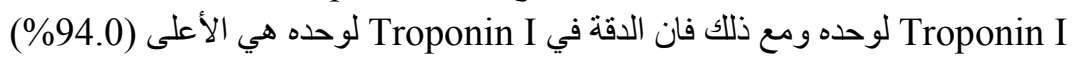

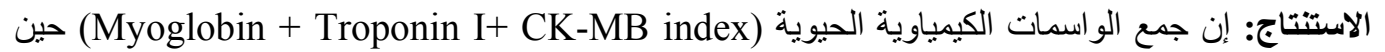
دخول المرضى في العناية المركزة بساعد كثير ا في تثخيص احتثاء العضلة القلبية الحاد.

S ymptoms and signs suggestive of acute myocardial infarction (AMI) and unstable angina which constitute acute coronary syndrome (ACS) are non specific and have low sensitivity for diagnosis of this condition ${ }^{1}$. The World Health Organization (WHO) definition and diagnosis of AMI, is currently two out of three: characteristic chest pain, diagnostic electrocardiogram changes and elevation of the biochemical markers in the blood samples ${ }^{2}$.

The electrocardiogram (ECG) may never show the classical features of ST elevation and new Q waves. Hence, in the early stage, there is no enough evidence in these patients for clear diagnosis and risk stratification ${ }^{3}$.

Biochemical marker identification which is sensitive and specific for myocardial ischemia and can easily and rapidly measured in serum would be clinically valuable ${ }^{3}$. Elevated levels of cardiac markers: Creatine kinase (CK-MB) activities (marker of necrosis), in addition to troponin I (marker of necrosis), and myoglobin (marker of muscle injury), could be useful in early diagnosis of acute coronary syndrome when patients admitted to coronary care unit (CCU) ${ }^{3}$.

Use of the combination of a marker that appears early (myoglobin) and either Creatine Kinase CK-MB isoenzyme (CK-MB) or cardiac troponin I (TnI) may facilitate rapid exclusion of AMI and enable discharge of patients who do not require prolonged observation ${ }^{4}$. Myoglobin is advantageous because it appears 1 to 2 hours after symptom onset, and studies have demonstrated its high sensitivity for detection of AMI within the first few hours after presentation ${ }^{(4)}$. However, use of myoglobin alone has significant limitations. Myoglobin has low specificity for cardiac necrosis in patients with renal failure or skeletal muscle trauma ${ }^{5}$. Also, given that serum myoglobin rises and falls quickly in AMI, a single measurement at presentation may be normal for patients who present early and who present 24 hours after symptom onset $^{6}$. On the other hand, CK-MB and cTnI appear 3 to 6 hours after symptom onset and remain elevated for 
24 to 36 hours and 7 to 10 days, respectively ${ }^{7}$. However, these markers must be ordered as a panel in the ED because no single marker meets all criteria for an ideal marker of AMI diagnosis for all patients who arrive at the ED at various times after the onset of the symptoms ${ }^{8}$.

The aim of this study was to evaluate the importance of combination of biochemical markers in patients with Acute Coronary Syndrome (ACS) and to determine the optimal biochemical strategy for highly sensitive, early diagnosis of myocardial injury.

\section{Subjects and methods}

This study was carried out in Ibn- Sena Teaching Hospital in Mosul from January 2008 to November 2008. It was carried out on 249 patients with Acute Coronary Syndrome (ACS) who were presented with chest pain where $193(77.5 \%)$ patients with a diagnosis of possible Acute Myocardial Infarction (AMI) and 56 (22.5\%) patients with Unstable Angina (UA) . A control group that includes 111 apparently healthy subjects who attended the Out-Patient department was chosen for comparison. None of the control subjects had any chronic diseases and they were not taking regular medicine. All patients who admitted to the CCU were with provisional diagnosis of ACS. The patients were looked for risk factors, "Smokers" were defined as patients currently smoking at the time of admission; Hypertension was defined by self-report of a diagnosis and use of an anti-hypertensive medication, or if systolic blood pressure $>140 \mathrm{mmHg}$ or if diastolic blood pressure $>90$ $\mathrm{mmHg}^{9}$; "Diabetes" as patients on insulin or taking oral hypoglycemic agent $^{10}$; " Hypercholesterolemia " as total cholesterol of $>5.0 \mathrm{mmol} / \mathrm{L}$ on admission $^{11}$. A family history for CHD is considered positive if relatives have experienced an MI prior to the age of 50 in men, and 55 in women ${ }^{1}$.

History of ischemic heart diseases is defined as any group of acute or chronic cardiac disabilities resulting from insufficient supply of oxygenated blood to the heart, or is a group of diseases characterized by reduced blood supply to the heart muscle usually due to coronary artery disease ( atherosclerosis of coronary arteries) ${ }^{11}$. Male gender and obesity were also considered as risk factors ${ }^{1}$.

All patients had cardiac markers tested within 12 hours post chest pain $^{12}$. Their ECG was assessed and any ischemic or progressive changes were documented ${ }^{12}$. Anthropometric Measurements were also taken. The socioeconomic state was grouped into low, medium and good. The study was carried out with the cooperation of senior cardiologist in Coronary Care Unit (CCU). On admission, patients satisfying two out of the three criteria of WHO were considered as having myocardial infarction ${ }^{2}$. The definitive diagnosis of myocardial infarction required all three criteria to be satisfied. Patients with chest pain and non-Q ECG pathology but with no changes in cardiac enzymes were diagnosed as having unstable angina ${ }^{13}$. The case notes were analyzed and 
information regarding the duration of chest pain, risk factors, socioeconomic status, Body mass index and ECG changes were obtained on a purpose designed data collection sheet.

About $10 \mathrm{ml}$ of venous blood were collected from patients on admission to the CCU. The blood samples were collected in vials. Blood allowed to clot fully by leaving for 15 minutes in water bath at $37{ }^{\circ} \mathrm{C}$, then serum was separated by centrifugation at 3000 rpm for 10 minutes. The serum sample was divided into two aliquots and stored at $-20{ }^{\circ} \mathrm{C}$. The first aliquot was for analysis of (CK) and CK-MB activities using BIOLABO CK-NAC UV method and BIOLABO CK- MB UV method respectively (in the department of biochemistry) ${ }^{14}$. The second aliquot was for analyses of troponin I and myoglobin using ELISA monoclonal antibody (Biochek, Foster City, USA) for both parameters ${ }^{15,16}$. The upper reference limits for the quantitative cardiac markers used in this study were: CK activity $174 \mathrm{U} / \mathrm{L}$ for men and $140 \mathrm{U} / \mathrm{L}$ for women; CKMB activity $\geq 25 \mathrm{IU}$; Troponin $\geq$ $0.4 \mathrm{ng} / \mathrm{mL}$ and myoglobin $\geq 54.5$ $\mathrm{ng} / \mathrm{mL}$. CK ratio value or index (CK$\mathrm{MB} / \mathrm{CK}) \times 100 \geq 6 \%$ is considered suggestive for AMI.

Statistical analyses: The collected data were analyzed statistically by chi square, unpaired t-test and analysis of variance (ANOVA) test. The cut-off values for all biochemical markers were determined by Receiver Operating Characteristics (ROC) curve analysis. A ROC is a graphical representation of the tradeoff between the true positive and false positive rates for every possible cut off of the test result. In essence, the ROC curve is the tradeoff between sensitivity and specificity ${ }^{17}$. A large area under curve (AUC), as shown in the table, means the test being assessed to a better diagnostic test. If the area is 1.0 , the test has both $100 \%$ sensitivity and $100 \%$ specificity and represents an ideal test. If the area is 0.5 , the test has $50 \%$ sensitivity and $50 \%$ specificity the same as getting heads on the flip of a coin. Therefore, the closer the AUC is to 1.0 , the better the test is for diagnosis ${ }^{17}$. The values for: sensitivity, specificity, positive predictive value (PPV), negative predictive value (NPP) were also calculated $^{18}$. All results were considered significant at $p<0.05$.

The study received the agreement of the Ethical committee of Nineveh Governorate Health Department and approval of Mosul College of Medicine- Postgraduate Studies Committee. Subjects were informed about the purpose of the study and oral consent was obtained from the patients and the controls after the study had been explained to them.

\section{Results}

\section{Description of Study Sample}

As shown in Table 1, the age of study subjects ranged between 26 and 90 years. The mean age in MI, UA patients and controls were $55.4 \pm 10$, $56.6 \pm 12.2$ and $57.3 \pm 11.9$ years respectively. There was male preponderance among MI cases (male to female ratio $1.76 / 1)$ while the ratio in UA cases was $(0.65 / 1)$ which means that UA is more frequent in females 
than males. BMI $25-30 \mathrm{~kg} / \mathrm{m}^{2}$ was present in $52.3 \%$ and $53.6 \%$ of $\mathrm{MI}$ and UA respectively, while 24.4 and $10.7 \%$ of MI and UA respectively were obese. The mean duration of UA was shorter than that of MI.

Frequency distribution of the risk factors among the studied patients

There were no significant differences between MI and UA cases in the prevalence rate of diabetes mellitus, hypercholesterolemia, cigarette smoking and family history of myocardial ischemia. Obesity and history of previous attack of myocardial ischemia were more frequent among MI cases $(24.4 \%$ and $30.6 \%$ ) compared to unstable angina cases $(10.7 \%$ and $14.3 \%$ respectively). More than $30 \%$ of patients had more than four risk factors (Table 2).

\section{Using Test Combinations}

At time of admission to coronary care unit, the combination of serum troponin I, myoglobin, CK activity, CK-MB activity and CK-MB index was performed. The optimal cut-off values determined by selecting the point on each curve at maximum curvature in ROC curve for each of 5 parameters with reasonable validity (Figure 1).

As shown in Table 3. serum troponin I was the most valid test when used alone in differentiating MI from unstable angina cases. The optimal cutoff value of each of 4 tests with reasonable validity were used to define single test criteria. After that, combination test criteria were used to improve the specificity of diagnosis by considering a subject as positive if the test positive on both criteria, otherwise the subject will be considered negative.

The serum troponin I was used in combination with each of the remaining 4 criteria and the test performance was assessed. All combinations were associated with higher specificity than that of serum troponin I alone. However, the accuracy of serum troponin I alone $94.0 \%$ was higher than the accuracy of all other combinations (Table 4). In this study, a large proportion of unstable angina ( 33 patients from 89 unstable angina patients), which is $13.2 \%$ of total (249 ACS patients), would be reclassified as having acute myocardial infarction due to utilizing cardiac markers. All combinations were associated with higher or equal specificity than that of serum troponin I alone (91.1\%), while the accuracy of serum troponin I alone $(94.0 \%)$ was higher than the accuracy of all other combinations.

\section{Cardiac Biochemical Markers Combination}

Triple combination of TnI, myoglobin with $\mathrm{CK}-\mathrm{MB} / \mathrm{CK}$ Ratio offered a high improvement over the combination of TnI and myoglobin testing recording (triple panel sensitivity, 91.2\%; specificity, $96.45 \%$ and highest accuracy $92.4 \%$ ) for diagnosis of myocardial infarction which means the best combination among others (Table 4). 
Table 1. Frequency distribution of the study sample by socio-demographic variables

\begin{tabular}{|c|c|c|c|c|c|c|}
\hline & \multicolumn{2}{|c|}{ Control $(\mathrm{n}=111)$} & \multicolumn{2}{|c|}{ MI $(n=193)$} & \multicolumn{2}{|c|}{ UA $(n=56)$} \\
\hline & No. & $\%$ & No. & $\%$ & No. & $\%$ \\
\hline \multicolumn{7}{|l|}{ 1. Age (years) } \\
\hline$<50$ & 24 & 21.6 & 32 & 16.6 & 11 & 19.6 \\
\hline $50-59$ & 26 & 23.4 & 75 & 38.9 & 23 & 41.1 \\
\hline $60-69$ & 43 & 38.7 & 58 & 30.1 & 13 & 23.2 \\
\hline$\geq 70$ & 18 & 16.2 & 28 & 14.5 & 9 & 16.1 \\
\hline Mean \pm SD & \multicolumn{2}{|c|}{$57.3 \pm 11.9$} & \multicolumn{2}{|c|}{$55.4 \pm 10.0$} & \multicolumn{2}{|c|}{$56.6 \pm 12.2$} \\
\hline Range & \multicolumn{2}{|c|}{$30-79$} & \multicolumn{2}{|c|}{$26-80$} & \multicolumn{2}{|c|}{$26-90$} \\
\hline \multicolumn{7}{|l|}{ 2. Gender } \\
\hline Male & 58 & 52.3 & 123 & 63.7 & 22 & 39.3 \\
\hline Female & 53 & 47.7 & 70 & 36.3 & 34 & 60.7 \\
\hline Male to Female ratio & \multicolumn{2}{|c|}{ 1.09:1 } & \multicolumn{2}{|c|}{$1.76: 1$} & \multicolumn{2}{|c|}{$0.65: 1$} \\
\hline \multicolumn{7}{|l|}{ 3. BMI $\left(\mathrm{kg} / \mathrm{m}^{2}\right)$} \\
\hline Normal (18.5-25) & 52 & 46.8 & 45 & 23.3 & 20 & 35.7 \\
\hline Overweight (25-30) & 57 & 51.4 & 101 & 52.3 & 30 & 53.6 \\
\hline Obese $(>30)$ & 2 & 1.8 & 47 & 24.4 & 6 & 10.7 \\
\hline \multicolumn{7}{|l|}{ 4.Socio-economic status } \\
\hline Low & 44 & 39.7 & 84 & 43.5 & 32 & 57.1 \\
\hline Medium & 46 & 41.4 & 56 & 29.0 & 16 & 28.6 \\
\hline High & 21 & 18.9 & 53 & 27.5 & 8 & 14.3 \\
\hline $\begin{array}{l}\text { 5. Duration of pain } \\
\text { Mean } \pm \text { SD (hour) }\end{array}$ & & & \multicolumn{2}{|c|}{$7.63 \pm 2.61$} & \multicolumn{2}{|c|}{$5.34 \pm 1.52 *$} \\
\hline
\end{tabular}

*Significant differences from MI data at $P<0.05$ 
Table 2. Frequency distribution of the risk factors among the studied patients

\begin{tabular}{|l|l|l|l|l|l|}
\hline \multirow{2}{*}{ Risk factors } & \multicolumn{2}{|l|}{ MI (n=193) } & \multicolumn{2}{l|}{ UA (n=56) } & \multirow{2}{*}{-value } \\
\cline { 2 - 6 } & No. & $\mathbf{\%}$ & No. & $\mathbf{\%}$ & \\
\hline Hypertension & 107 & 55.4 & 24 & 42.9 & NS \\
\hline Diabetes mellitus & 67 & 34.7 & 21 & 37.5 & NS \\
\hline Hypercholesterolemia & 61 & 31.6 & 11 & 19.6 & NS \\
\hline $\begin{array}{l}\text { Family history of } \\
\text { Ischemic heart disease }\end{array}$ & 35 & 18.1 & 10 & 17.9 & NS \\
\hline $\begin{array}{l}\text { Previous attack of } \\
\text { Ischemic heart disease }\end{array}$ & 59 & 30.6 & 8 & 14.3 & 0.008 \\
\hline $\begin{array}{c}\text { Cigarette smoking } \\
\text { Obesity }\end{array}$ & 64 & 33.2 & 19 & 33.9 & NS \\
\hline Gender (male) & 123 & 63.7 & 22 & 39.3 & 0.001 \\
\hline
\end{tabular}

$\mathrm{NS}=$ Not significant according to Chi-square test

Table 3. ROC area for the measured parameters for the differentiation of MI from $\mathrm{UA}$ in cases with ischemic heart disease.

\begin{tabular}{|c|c|c|c|}
\hline Parameters & Area & $p$-value & 95\% C.I. \\
\hline $\begin{array}{r}\text { Serum CK }(\mathrm{U} / \mathrm{L}) \\
147.0 \text { Optimal cut-off value }\end{array}$ & 0.886 & $<0.001$ & $0.840-0.931$ \\
\hline $\begin{array}{r}\text { Serum CK-MB (U/L) } \\
9.0 \text { Optimal cut-off value }\end{array}$ & 0.865 & $<0.001$ & $0.815-0.915$ \\
\hline $\begin{array}{l}\text { Serum myoglobin }(\mathrm{ng} / \mathrm{mL}) \\
52.5 \text { Optimal cut-off value }\end{array}$ & 0.896 & $<0.001$ & $0.847-0.945$ \\
\hline $\begin{array}{r}\text { Serum troponin I }(\mathrm{ng} / \mathrm{mL}) \\
1.55 \text { Optimal cut-off value }\end{array}$ & 0.924 & $<0.001$ & $0.874-0.973$ \\
\hline $\begin{array}{r}\text { CK-MB/CK Ratio or } \\
\text { Index } \\
2.18 \text { Optimal cut-off value }\end{array}$ & 0.794 & $<0.001$ & $0.736-0.852$ \\
\hline
\end{tabular}


Table 4. The validity parameters of the cut-off value for troponin alone and in combination with the other measured parameters when used to differentiate MI from UA in cases with ischemic heart disease

\begin{tabular}{|r|c|c|c|r|r|r|}
\hline & & & & $\begin{array}{r}\text { PPV at } \\
\text { pretest } \\
\text { prob. } \\
50 \%\end{array}$ & $\begin{array}{r}\text { PPV at } \\
\text { pretest } \\
\text { prob. }= \\
90 \%\end{array}$ & $\begin{array}{r}\text { NPV at } \\
\text { pretest } \\
\text { prob. }= \\
10 \%\end{array}$ \\
\hline Troponin I (ng/mL) & 94.8 & 91.1 & 94.0 & 91.4 & 99.0 & 99.4 \\
\hline Troponin I+ CK & 88.1 & 94.6 & 89.6 & 94.2 & 99.3 & 98.6 \\
\hline Troponin I+ Myoglobin & 88.1 & 91.1 & 88.8 & 90.8 & 98.9 & 98.6 \\
\hline Troponin I + CK-MB & 80.8 & 96.4 & 84.3 & 95.7 & 99.5 & 97.8 \\
\hline $\begin{array}{r}\text { Troponin I +CK-MB/CK } \\
\text { Ratio or Index }\end{array}$ & 93.8 & 91.1 & 93.2 & 91.3 & 99.0 & 99.3 \\
\hline
\end{tabular}

Table 5. The validity parameters of the cut-off value for the triple combination of the measured parameters when used to differentiate MI from UA in cases with ischemic heart disease

\begin{tabular}{|r|c|c|c|c|c|c|}
\hline Combinations of parameters & Sensitivity & Specificity & Accuracy & $\begin{array}{c}\text { PPV at } \\
\text { pretest } \\
\text { prob. }= \\
50 \%\end{array}$ & $\begin{array}{c}\text { PPV at } \\
\text { pretest } \\
\text { prob. }= \\
90 \%\end{array}$ & $\begin{array}{c}\text { NPV at } \\
\text { pretest } \\
\text { prob. } \\
10 \%\end{array}$ \\
\hline CK + CK-MB + Myoglobin & 77.2 & 94.6 & 81.1 & 93.5 & 99.2 & 97.4 \\
\hline CK + CK-MB + Troponin I & 78.9 & 96.4 & 82.7 & 95.6 & 99.5 & 97.6 \\
\hline CK + CK-MB + Ratio* & 83.4 & 83.9 & 83.5 & 83.8 & 97.9 & 97.9 \\
\hline CK-MB + Myoglobin + Troponin & 75.1 & 98.2 & 80.3 & 97.7 & 99.7 & 97.3 \\
\hline CK-MB + Myoglobin + Ratio* & 79.3 & 94.6 & 82.7 & 93.6 & 99.3 & 97.6 \\
\hline Myoglobin + Troponin I+ Ratio* & 91.2 & 96.4 & 92.4 & 96.2 & 99.6 & 99.0 \\
\hline
\end{tabular}

$*$ Ratio= CK-MB/CK Ratio or Index 


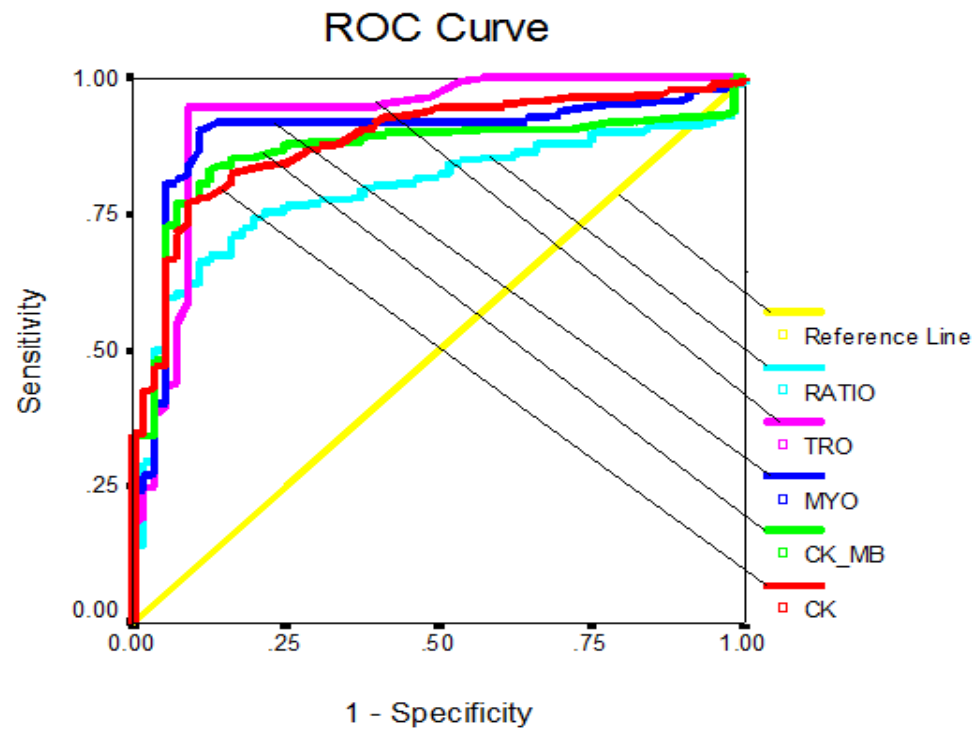

Figure 1. ROC curve for different cut-off values of selected parameters when used to diagnose MI from UA in subjects with ischemic heart disease

\section{Discussion}

The National Academy of Clinical Biochemistry (NACB) has recommended that the protocol for using cardiac markers in evaluation of patients with possible ACS should include an" early marker such as myoglobin or CK-MB, which is reliably increased in the blood within $6 \mathrm{~h}$ after symptoms onset, and a "definitive" marker ( such as TnI or TnT), which is increased in the blood after 6-9 $\mathrm{h}$ with a high sensitivity and specificity for myocardial injury and remains with abnormal levels for several days thereafter ${ }^{19}$. The use of combination of marker that appears early [myoglobin] and either CK-MB or cardiac troponin I may facilitate rapid exclusion of $\mathrm{MI}$ and enable discharge of patients ${ }^{20}$. As for diagnostic purposes, an algorithm applying a panel of biochemical markers reflecting different aspects in ACS appears to be a promising option for improving risk stratification $^{21}$. In contrast multimarker strategies incorporating CK-MB or myoglobin in combination with troponin I results have only been evaluated by few authors $^{20-24}$. However, it makes intuitive sense that combinations of two or more cardiac biomarkers increase the early predictive value of these types of strategies ${ }^{25}$.

In this study, four markers were used in addition to CM-MB index as criteria that favor the diagnosis and differentiation of MI from UA in cases of ACS, when equal to or higher than an optimal cut-off value. When the subject is positive in at least three of these 
tests he is considered to have diagnosis of AMI. Troponin I sensitivity was the highest one among other parameters with (99.4\%) negative predictive value. But however, at these cut-off values, the diagnostic predictive value for combination of two tests was less significant (Table 4).

In the present study, a combination of TnI and CK-MB index can achieve a diagnostic sensitivity of $93.8 \%$ for AMI with a 99.3\% negative predictive value at time of admission to $\mathrm{CCU}$, which is the highest diagnostic sensitivity among other combination. This is consistent with the study of Engel and Rockson where the sensitivity of combination of $\mathrm{TnI}$ and CK-MB index was $90.6 \%$ at time of presentation $^{24}$. However, the combination of myoglobin and $\mathrm{TnI}$ can achieve a diagnostic sensitivity of $88.1 \%$ for AMI with a $98.6 \%$ negative predictive value, at presentation to CCU which similar to the results of others ${ }^{23,27,28}$. Thus, the combination of a highly sensitive marker such as myoglobin with a highly specific marker such as troponin might optimize diagnostic accuracy.

The triple combination of the measured parameters when used to diagnose patients with ACS showed combination of myoglobin, troponin I and $\mathrm{CK}-\mathrm{MB}$ ratio recorded high sensitivity $91.2 \%$ with a specificity of $96.45 \%$ and highest accuracy $92.4 \%$ and high positive predictive value $99.6 \%$. These results are in line with the study of Hsu et al where a triple marker panel of myoglobin, TnI and CK-MB had a sensitivity of $93 \%$ and specificity of $95 \%$ and the study of Rathore et al which showed a sensitivity of $85.7 \%$ and specificity of $96.5 \%$ and positive predictive value $92.3 \%$ for the same combination $^{20,29}$.

Most studies have compared only two or three markers at the same time and have not compared them with the initial electrocardiogram.

In conclusion, no single biochemical marker can be used to predict diagnosis in AMI patients, therefore, it is conceivable that combination of biochemical markers may help for this purpose. Combination of Troponin I, myoglobin and CK-MB index can achieve the best diagnostic yield.

\section{References}

1. Bloomfield P, Bradbury A, Grubb NR, et al. Cardiovascular diseases. In: Davidson's Principles and Practice of Medicine. Boon NA, Colledge NR, Walker BR Eds. 20th ed. Churchill Livingstone. Edinburgh. 2006. Pp 519-646.

2. World Health Organization. Report of the Joint of Cardiology /World Health Organization task Force on Standardization of Clinical Nomenclature. Nomenclature and criteria for diagnosis of ischemic heart disease. Circulation 1979;59:607-9.

3. Panteghini M. Role and importance of biochemical markers in clinical cardiology. Eur Heart J 2004;25(14):1187-96. 
4. Brogan GX, Friedman S, McCuskey C, et al. Evaluation of a new rapid quantitative immunoassay for serum myoglobin versus $\mathrm{CK}-\mathrm{MB}$ for ruling out $\mathrm{AMI}$ in the emergency department. Ann Emerg Med 1994;24:665-71.

5. De Winter RJ, Koster RW, Sturk $A$, et al. Value of myoglobin, troponin $\mathrm{T}$, and $\mathrm{CK}-\mathrm{MB}$ mass in ruling out an AMI in the emergency room. Circulation 1995;92:3401-7.

6. Gilkeson G, Stone MJ, Waterman $M$, et al. Detection of myoglobin by radioimmunoassay in human sera: its usefulness and limitations as an emergency room screening test for acute myocardial infarction. Am Heart J 1978;95:70-7.

7. Ruseva A. Laboratory diagnosis of acute myocardial infarction. Trakia J Sci 2005;3(1):8-14.

8. Straface AL, Myers JH, Kirchick HJ, et al. A Rapid Point-of-Care cardiac marker testing strategy facilitates the rapid diagnosis and management of chest pain patients in the emergency department. Ann J Clin Pathol 2008;129(5):788-95.

9. Awtry EH, Locscalo J. Coronary heart disease. In: Capenter $\mathrm{C}$; Griggs RC; and Locscalo J. CECEL Essential of Medicine. 6th ed.2004. Elsevier. Saunders Inc. Philadelphia. Pp 87-173.

10. Larsson H, Bergund G, Lindgard $F$, et al. Comparison of ADA and WHO criteria for diagnosis of diabetes and glucose intolerance. Diabetologia 1998;41:1124-5.

11. Wood D, Durrington P, Poulter N. Joint British recommendations on prevention of coronary heart disease in clinical practice. Heart 1998;80 (Suppl.2):1-29.

12. Innasimutthu AL, Siddhi SS, Rao GKB. Clinical presentation and ECG changes - how good is it in diagnosing troponin positive acute coronary syndrome. Anatol J Cardiol 2007; Suppl 1:168-70.

13. Chiu WK, Chan SH, Cheng CK, et al. Troponin I, myoglobin, and mass concentration of creatine kinase-MB in acute myocardial infarction. Q J M 1999;92:711-8.

14. Panteghini M, Renze B. Enzymes. In: Teitz Fundamentals of Clinical Chemistry (Burtis CA, Ashood ER and DE Bruns, Eds). 6th ed. WB Saunders. Philadelphia 2008;P 320.

15. Uotila M, Ruoslathi E, Engvall E. Two-site sandwich enzyme immunoassay with monoclonal antibodies to human alpha fetoprotein. J Immunol. Meth 1981;42:11-15.

16. Cummins B, Auckland ML, Cummins. Cardiac-specific troponin-I radio-immunoassay in the diagnosis of acute myocardial infarction. Am. Heart. J 1987;113:1333-44.

17. Chap TL. Logistic regression. In: Introductory Biostatistics. Wiley. New Jersey. 2003. P 337.

18. Al-Khafaji AM. Epidemiology in evidence- based clinical practice. A workbook for independent study in clinical epidemiology. 1998. Mosul, Iraq. Pp 70-73.

19. Wu AHB, Apple FS, Gibler WB, et al. National academy of 
clinical biochemistry standards of laboratory practice: recommendations for the use of cardiac markers in coronary artery diseases. Clin Chem 1999;45:1104-21.

20. Rathore S, Knowles P,. Mann APS. Is it safe to discharge patients from accident and emergency using a rapid point of care triple cardiac marker test to rule out acute coronary syndrome in low to intermediate risk patients presenting with chest pain? Eur. J. Intern. Med. 2008;19:537-40.

21. Cameron SJ, Sokoll LJ, Laterza $\mathrm{OF}$, et al. A multi-marker approach for the prediction of adverse events in patients with acute coronary syndromes. Clin Chim Acta 2007;376:168-73.

22. Newby K, Storrow A, Gibler B, et al. Bed side multimarker testing for risk stratification in chest pain units. The chest pain evaluation by creatine kinase$\mathrm{MB}$, myoglobin, and troponin I (CHECKMATE) study. Circulation 2001;103(14):1832-7.

23. McCord J, Nowak RM, McCullough PA, et al. Ninetyminute exclusion of acute myocardial infarction by use of quantitative point-of-care testing of myoglobin and troponin I. Circulation 2001;104(13):1483-8.
24. Yamamoto $\mathrm{M}$, Komiyama N, Koizumi $\mathrm{T}$, et al. Usefulness of rapid quantitative measurement of myoglobin and troponin $\mathrm{T}$ in early diagnosis of acute myocardial infarction. Circ. J. 2004;68: $639-44$.

25. Hollander JE. The Future of Cardiac Biomarkers. Emergency Medical Cardiac Research Education Group. 2005;4:1-7.

26. Engel G, Rockson SG. Rapid diagnosis of myocardial injury with troponin $\mathrm{T}$ and $\mathrm{CK}-\mathrm{MB}$ relative index. Mol. Diagn. Ther. 2007;11:109-16.

27. Higuchi $\mathrm{K}$, Abe S, Matsuoka T, et al. Usefulness of rapid quantitative cardiac troponin $\mathrm{T}$ and myoglobin assays for the diagnosis of acute myocardial infarction. J Cardiol 2003; 41(2):55-62.

28. Melanson SEF, Tanasijevic MJ, Jarolim P. Cardiac troponin assays. A View from the clinical chemistry laboratory. Circulation 2007;116:e501-4.

29. Hsu LF, Koh TH, Lim YL. Cardiac marker point-of-care testing: evaluation of rapid onsite biochemical marker analysis for diagnosis of acute myocardial infarction. Ann Acad Med Singapore 2000;29(4):421-27. 